\title{
Concerns about surgical skills slipping in younger doctors unfounded, say Canadian
}

\section{surgeons}

— Cite as: CMAJ 2019 January 7;191:E24-5. doi: 10.1503/cmaj.109-5696

Posted on cmajnews.com on Dec. 5, 2018.

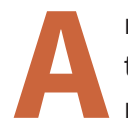

re young surgeons less dextrous than generations past? The argument recently got airtime in several mainstream news outlets thanks to surgeon Dr. Roger Kneebone, a professor of surgical education at Imperial College in London, England. He suggested that the trend toward increased screen time in childhood and adolescence, and decreased time working with one's hands, was to blame.

Canadian surgeons and educators disagree with Kneebone, however, and the science doesn't support the theory of a downturn in surgical skills. Dr. Teodor Grantcharov, a staff surgeon at St. Michael's Hospital and a professor of surgery at the University of Toronto, doesn't think surgical skills have decreased. He's tested surgeons' skills in several studies over the past 15 years to evaluate surgical training methods.

In each study, the breakdown has been roughly the same, he says. "Five percent are spectacular; about $8 \%$ are just terrible - there was something in their brains that didn't allow them to develop the fine motor skills. The rest improved with practice."

In fact, rather than having a harmful effect, Grantcharov points out, video games might give younger generations an edge. "Looking at the computer screen while you're executing a task is a fairly new thing for us surgeons. That's what computer games do and that's what you do in laparoscopic or minimally invasive surgery."

There is some evidence to support this theory. A 2017 study of 50 medical students showed those who played video

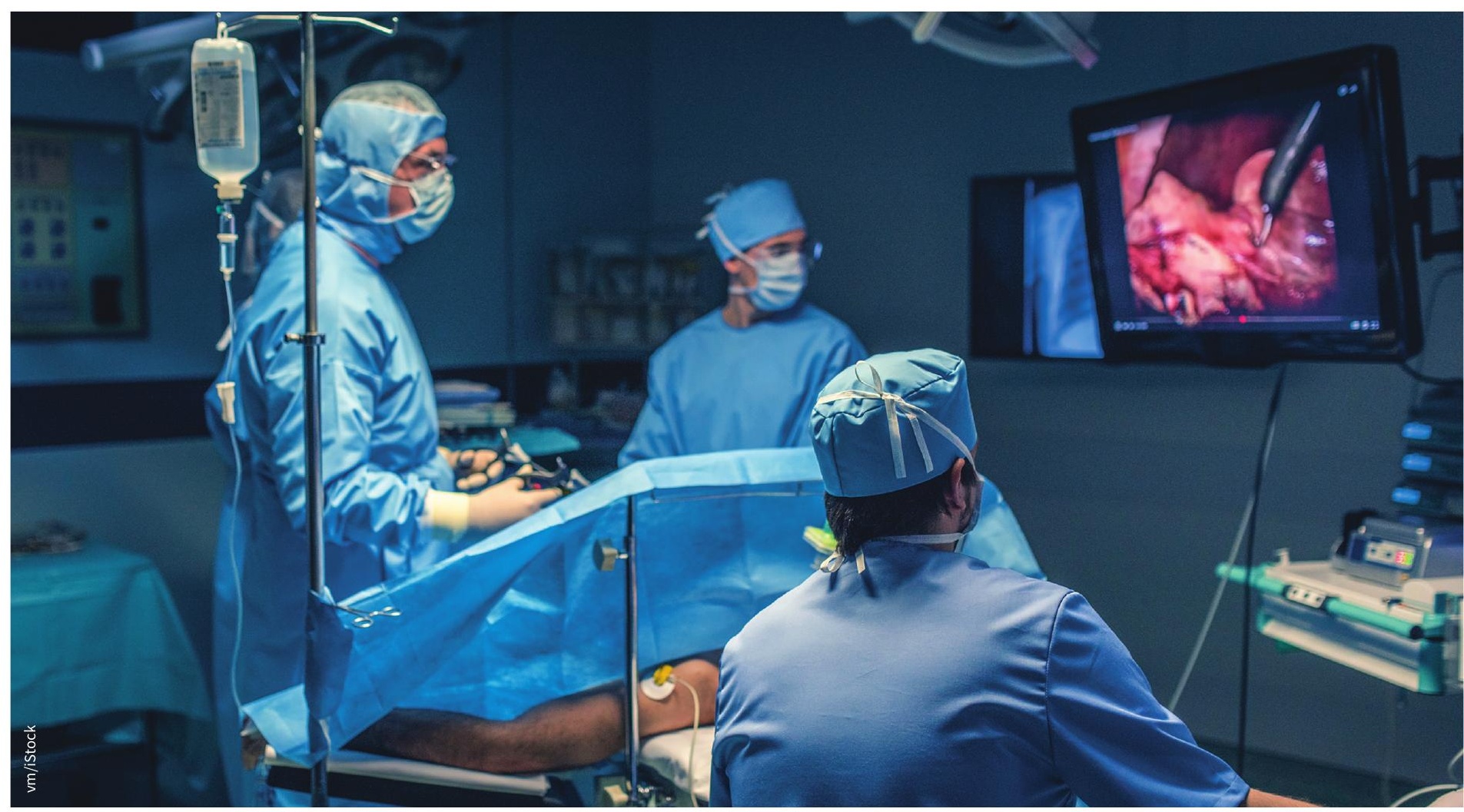

Younger doctors raised on video games may have an edge in performing fine motor skills while looking at a screen. 
games for 10 hours a week were faster at simulated renal artery cannulation than those who didn't play video games.

Dr. Shady Ashamalla, assistant professor of general surgery at the University of Toronto and a specialist in minimally invasive surgery at the Odette Cancer Centre, was surprised to see how much media play the comments from Kneebone received. "Usually, that type of energy comes from a study or some kind of published report," he says. As for the argument that younger surgeons lack dexterity in their hands, "I don't agree at all."

What has changed, in his view, is "the complexity of surgery based on the innovations that have been introduced." The rise of laparoscopic surgery means surgeons not only need to have dexterity in their hands but also the ability to "translate sizes and shapes from a screen into reality." Minimally invasive surgeries involve harder skills to master in many ways than open surgery. "It's not that the residents aren't as good; what we're trying to teach them is harder."

Given that the technical aspects of surgery have changed so drastically, however, Ashamalla thinks surgical residencies should be revamped to better teach and evaluate surgical skills. "Probably in the past, there's been a little bit more of a rubber stamp" to test residents' baseline technical skills before they write their licensing exams.

The move to competency-based teaching and evaluation is key, he argues. "In time, surgical training will not be about getting through $X$ number of years; it will be passing modules, whether that takes six months or one month, and then moving on to the next one." The historical paradigm of "see one, do one, teach one" no longer applies to today's learning environment, where surgeon trainees may spend months honing their skills in a simulation lab before they're deemed ready to go to the operating room, he adds.

At Queen's University, which has already made the switch to a competencybased curriculum, "there's much more of a focus on ensuring that the residents are getting specific experiences" rather than having students move through a timebased curriculum, says Dr. Dan Howes, director of the school's Clinical Simulation Centre.

Thanks to simulation centres, Howes adds, "medical students today have much more advanced opportunities to practise those technical skills, compared to previous generations." Howe notes, though, that there is much more to being a surgeon than being technically adept. Decision-making - knowing when to perform an operation, and how to adjust a planned course of action based on clinical findings - is more important and harder to master, says Howes.

There is one looming issue, however, with the potential to have a negative impact on manual surgical skills: the growth of robotics in surgery. Grantcharov worries that as robotics manufacturers urge surgical residents to learn on their systems, manual laparoscopic procedures will be neglected. Robotics surgery "doesn't have the same requirements for motor skills or manual dexterity," and he worries trainees could miss out on technical practice.

'I think we'll have to be mindful of not underestimating the value of proper training in minimally invasive surgery," even as robotics surgery increases in popularity, Grantcharov says. "We train pilots so that they can fly without autopilot, and we'll need to do the same for surgeons."

Wendy Glauser, Toronto, Ont. 